available in even the poorer microform readers. Electronic publishing is a new form of publication that some believe will solve the "library problem" and replace publications in both microforms and traditional print. Can the history of micropublishing be helpful in assessing how likely this is to happen? In some ways it probably can. Electronic publishing will not replace traditional publishing, but it will succeed to the extent that it can find applications that will provide useful alternatives to print and microforms.-Francis $F$. Spreitzer, University of Southern California.

Maack, Mary Niles. Libraries in Senegal; Continuity and Change in an Emerging $\mathrm{Na}$ tion. Chicago: American Library Assn., 1981, 280p. ISBN 0-8389-0321-5.

This is a short history of library, archive, and documentation development in Senegal, French West Africa. Senegal is particularly appropriate for historical attention: it has exerted a strong influence on its francophone neighbors, and its archives cover library activities from their early

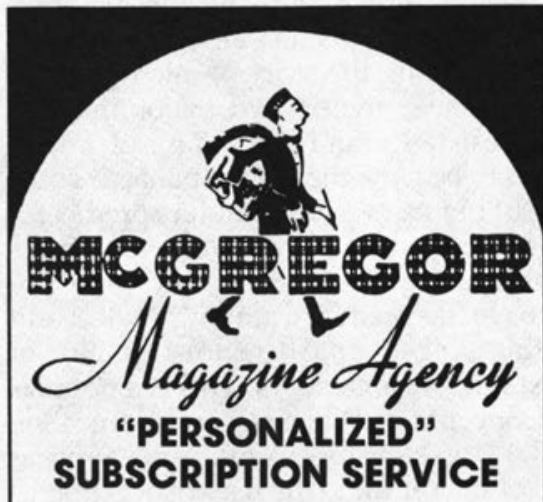

McGregor can simplify complex and time consuming problems of periodical procurement involving research, ordering, payments, renewals and record keeping. Prompt courteous service has been a tradition with McGregor since 1933.

Call or write for catalog today 815/734-4183

MCGREGOR MAGAZINE AGENCY Mount Morris, Illinois 61054 nineteenth century beginnings. Maack explains the heavy and continuous dependence on France in education and library science. The book is written in a positive and temperate manner; its aim is to understand and explain, not to evaluate or criticize. Maack is a University of Minnesota Library School professor, and this is an adaptation and summary of her doctoral dissertation.

Chapters are arranged chronologically and by type of library. Lists of acronyms and abbreviations are provided as well as tables, illustrations, glossary, bibliography, appendix, index, and footnotes. According to Maack, Senegalese archives and special and academic libraries more or less have prospered in this period, but public and school libraries have not, a common picture in developing countries and one reflecting priorities in France, also.

This is a work to be proud of within its self-imposed limitations. The author's energy and thoroughness in collecting information through interviews and library search in Senegal, France, and the United States are noteworthy. The book is fair and comprehensive. It is well written, well titled, judicious and meticulous, and seems to be almost completely error-free. It is supported by extensive bilingual notes and citations. The work mentions for the anglophone reader the influence of French policies and practices on West African development and certain of their contrasts with the Anglo-American influence on other West African nations. The conclusions are logically developed and illuminating.

Most of this reviewer's questions relate to Maack's presentation policies. The book's focus is narrowly on libraries, while their cultural and economic setting are only lightly touched on, perhaps too lightly. Further, Maack nearly omits the Arabic and vernacular Islamic culture, which still dominates the common people's lives. So the book represents an outsider's or colonialist's view. Little space is given to comparisons of nearby nations. Nor is the question faced that French library policies may have been applied primarily in the best interests of France rather 
than those of Senegal. Finally, the story ends at 1975, leaving the reader with natural questions about more recent developments.

The book is strongly recommended for research collections covering developing countries, West African, and library history.-John F. Harvey, International Library and Information Science Consultant, Lyndonville, Vermont.

Davies, Helen. Libraries in West Africa: a Bibliography. Hamden, Conn.: Shoe String, 1982. 170p. ISBN 3-598-10440-5.

This is a selective bibliography of Central West African librarianship. A third edition, with library history newly added, it covers the period through 1979. The book's objective is to provide access to information on West African library activities, with emphasis on practice, not general theory. Very little information is included on culture, scholarship, publishing, or related subjects. All scholarly levels are included, and most items are papers or short reports, not books. In total,
1,398 items are listed. Davies is a College of Librarianship-Wales faculty member with West African experience.

Following a section on West African libraries in general, arrangement is alphabetical by country, then classified by kind of library or library activity. Within subheadings, arrangement is in inverse chronological order. Item duplication is minimized. Libraries in general, library history, legislation, associations, libraries, buildings, collections, processes, surveys, national bibliography, reading, and archives are covered. Benin, Cameroun, Cape Verde Islands, The Gambia, Ghana, Guinea, the Ivory Coast, Liberia, Mali, Mauritania, Niger, Nigeria, Senegal, Sierra Leone, Togo, and Upper Volda are included. A list of twenty-seven West African library periodicals, conference index, and name index conclude the book.

The page division is Nigeria, 46 percent; West African libraries in general, 23 percent; Ghana, 8 percent; Senegal, 4 percent; Sierra Leone, 4 percent; and the remaining twelve countries, 15 percent

\section{UNITED NATIONS PUBLICATIONS}

\section{Publications Catalogue sent free on request}

\section{BASIC TOOLS FOR LIBRARIANS}

Current Bibliographical Information. Monthly listing of publications as well as articles selected from some 900 worldwide periodicals on current topics of interest to the United Nations.

Annual subscription: $\$ 60.00$

Single issues: $\$ 6.00$

UNDOC Current Index (United Nations Documents Index). Issued in 10 monthly issues, plus one annual cumulation, giving a comprehensive coverage of UN documentation, with a checklist, full bibliographic descriptions and subject, author and title indexes.

Annual subscription: $\$ 120.00$ Single issues: $\$ 14.00$

The above reference sources as well as many others may be ordered individually or by placing a Standing Order with UN Publications. Please request our latest Publications in Print catalogue and Standing Order brochure free of charge.

\section{SPECIAL ALERT FOR LIBRARIANS} COMING TO SLA...

Plan on attending a special United Nations documents training workshop sponsored by the UN Dag Hammarskjold Library. Also, plan on visiting the eight booths of the UN Family of Specialized Agencies (Booths Peninsula C and $211-212,219-220$ ) and get our new Library Publications brochure.

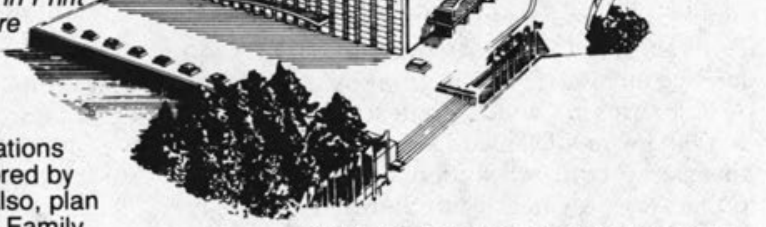

UNITED NATIONS PUBLICATIONS

Room DC2-853, New York, N.Y. 10017 Palais des Nations, 1211 Geneva 10, Switzerland 